\title{
Decarbonylation of Carboxylic Acids over H-Mordenite
}

\author{
Ziqiao Zhou, ${ }^{\text {ab }}$ Hongchao Liu, ${ }^{\mathrm{a}}$ Zhiyang Chen, ${ }^{\mathrm{ab}}$ Wenliang Zhu*a and Zhongmin Liu* ${ }^{\mathrm{ab}}$
}

a) National Engineering Laboratory for Methanol to Olefins, Dalian National Laboratory for Clean Energy, iChEM, Dalian Institute of Chemical Physics, Chinese Academy of Sciences, Dalian 116023, P.R. China.

b) University of Chinese Academy of Sciences, Beijing 100049, P.R. China

E-mail: *wlzhu@dicp.ac.cn, *liuzm@dicp.ac.cn

\section{Supporting Information}

\section{Experimental}

\section{Reversibility derivation for decarbonylation of acetic acid}

Table.S1. Channel dimension of zeolites used in this study

Table.S2. Surface area and pore volume of NaH-MOR samples

Figure.S1. XRD characterization of zeolites

Figure.S2. IR spectra of H-MOR and py-H-MOR

Figure.S3. Time-on-stream of acetic acid decarbonylation

Figure.S4. TG analysis of spent H-MOR and py-H-MOR

Figure.S5. Ratio of formation rate of $\mathrm{CO}$ to methyl acetate

Figure.S6. Reaction of ethyl acetate over py-H-MOR

Figure.S7. IR spectra and $\mathrm{Na}^{+}$content of $\mathrm{NaH}-\mathrm{MOR}$

Figure.S8. XRD characterization of NaH-MOR and their parent samples.

Figure.S9. Correlation between number of acids and ethylene formation rate 
Figure.S10. Formation rate of $\mathrm{CO}$ and ethylene over $\mathrm{H}-\mathrm{MOR}$ and py-H-MOR

Figure.S11. Ratio of formation rate of CO to ethylene over H-MOR and py-H-MOR

Figure.S12. Ratio of formation rate of CO to ethylene over H-ZSM5, H-ZSM35, H-Beta and H-Y.

Figure.S13. Capacity of ethanol dehydration over py-H-MOR

Figure.S14. Formation rate of $\mathrm{CO}$ and propylene and the ratio of $\mathrm{CO}$ to propylene

\section{Experimental:}

The powder of H-ZSM5 ( 20), H-ZSM35 (Si/Al 20), H-Y (Si/Al 4) and H-Beta ( $\mathrm{Si} / \mathrm{Al} \sim 20)$ were commercially obtained from NanKai University Catalyst Ltd. in $\mathrm{H}^{+}$form and used as received. Na-MOR $(\mathrm{Si} / \mathrm{Al} \sim 16)$ was purchased from YanChang-ZhongKe Catalyst Ltd. The X-ray diffraction characterizations of these zeolites are presented in supporting information (Figure.S1), which were achieved by PANalytical X'Pert PRO X-ray diffractometer with $\mathrm{Cu} \mathrm{K} \alpha$ radiation $(\lambda=0.154059 \AA)$ at $40 \mathrm{kV}$ and $40 \mathrm{~mA}$ from 5 to $60^{\circ}$

Deuterated pyridine (>99.5 atom \%d, pyridine- $\mathrm{d}_{5}$ ) was purchased from BeijingChongxi High-Tech Incubator, Co., Ltd. Deuterated acetic acid (>99.5 atom \%d, $\left.\mathrm{CD}_{3} \mathrm{COOD}\right)$ was purchased from Sigma-Aldrich, Co. Pyridine, acetic acid, propionic acid and ethyl acetate were purchased from Tianjin Kermel Co., Ltd. The flow rates of $\mathrm{N}_{2}, \mathrm{Ar}$ and $\mathrm{CO}$ were controlled by individual mass-flow-controller (SLA5850, Brooks Instrument). The liquid feed was introduced into the reactor in its gas phase by passing carrier Ar through the bubbler. The flow rate of carrier Ar was also controlled by a mass-flow-controller (5850E, Brooks Instrument). The partial pressure of the liquid supply was controlled by the temperature of water that heating the bubbler. The line connecting the bubbler to the reactor was heated to 
prevent the condensation of the gas-phase reactant.

To obtain H-MOR, the purchased Na-MOR was first calcined at $823 \mathrm{~K}$ for $4 \mathrm{~h}$ in air to remove the residual templates. $\mathrm{NH}_{4} \mathrm{MOR}$ was obtained by the ion-exchange of Na-MOR by $\mathrm{NH}_{4} \mathrm{NO}_{3}$ solution $(1.0 \mathrm{~mol} \mathrm{~L}-1$, solution/zeolite mass ratio=10) at $353 \mathrm{~K}$ for $2 \mathrm{~h}$, then filtered and washed by deionized water. The ion-exchange process was repeated twice. After drying at $393 \mathrm{~K}$ overnight, $\mathrm{NH}_{4} \mathrm{MOR}$ was characterized by $\mathrm{X}$-ray fluorescence spectrometry to ensure the complete $\mathrm{Na}^{+}$removal. $\mathrm{NH}_{4} \mathrm{MOR}$ powder was then pressed into particles of $40-60$ mesh and calcined at $773 \mathrm{~K}$ for $3 \mathrm{~h}$ in flowing dry air to obtain $\mathrm{H}-\mathrm{MOR}$.

Partially $\mathrm{Na}^{+}$ion-exchanged MOR (NaH-MOR) was obtained by a single ion-exchange process. $15 \mathrm{~g} \mathrm{NH}_{4} \mathrm{MOR}$ was treated by $\mathrm{NaNO}_{3}$ aqueous solution with different concentration (0.005-0.1 mol L $\left.\mathrm{L}^{-1}\right)$. The sample was then washed by deionized water, filtered and dried at $393 \mathrm{~K}$ overnight. $\mathrm{NaH}-\mathrm{MOR}$ was treated in the same method of $\mathrm{NH}_{4} \mathrm{MOR}$ to $\mathrm{H}-\mathrm{MOR}$ to obtain NaH-MOR.

Catalyst (40-60 mesh) was loaded in a stainless steel fix-bed reactor (7 mm i.d.) and it was separated from quart sand by glass wool. Two K-type thermal couples were used to control the reaction temperature. Catalyst was heated at $673 \mathrm{~K}$ for $2 \mathrm{~h}$ in flowing $\mathrm{Ar}\left(30 \mathrm{ml} \mathrm{min}^{-1}\right)$ to remove the moisture, then it was cooled to $573 \mathrm{~K}$ for pyridine treatment if necessary.

To obtain pyridine-treated sample, after catalyst was dried at $673 \mathrm{~K}$ and cooled to $573 \mathrm{~K}$, it was treated by $98 \% \mathrm{~N}_{2} / 2 \%$ pyridine mixture $\left(30 \mathrm{ml} \mathrm{min}^{-1}\right)$ at $573 \mathrm{~K}$ for $2 \mathrm{~h}$, followed by treatment of pure $\mathrm{N}_{2}\left(60 \mathrm{ml} \mathrm{min}{ }^{-1}\right)$ for $2 \mathrm{~h}$ to remove the residual pyridine. The procedure of pyridine treatment could be also found in previous literature ${ }^{1}$.

In situ reflectance infrared Fourier transform (DRIFT) spectroscopy was performed on Bruker Tensor 27 instrument that equipped with MCT detector and an in situ diffuse reflectance attachment. The power of pyridine-treated H-MOR was placed in the in situ 
DRIFT cell that covered by ZnSe window. Then the catalyst was heated at $473 \mathrm{~K}$ for $3 \mathrm{~h}$ under vacuum condition to remove moisture. Afterwards the catalysts was wetted by acetic acid, heated to $373 \mathrm{~K}$ for $10 \mathrm{~min}$ under vacuum to remove the physically absorbed acetic acid. The in situ absorbance spectra were obtained by collecting 16 scans at $4 \mathrm{~cm}^{-1}$ resolution 10 min after the temperature reached at set point.

Products in continuous-flow experiments were analyzed by an online gas-chromatograph (GC, Agilent, 7890B) that contains a HP-PLOT/Q $(30 \mathrm{~m} \times 0.53 \mathrm{~mm} \times 40 \mu \mathrm{m})$ capillary column connected to flame-ionization detector (FID), and a TDX-01 packed column connected to thermo-conductivity detector (TCD). The lines that connect the outlet of reactor and inlet of gas-chromatograph was heated to avoid the condensation of the products. The products that using fully deuterated acetic acid as reactant were extracted by passing effluent into acetone. The mixture was then analyzed by GC-MS (Agilent 7890/5975C).

The conversion of reactants and the selectivity of products were calculated by following equations:

$$
\begin{aligned}
& \text { Conversion }(\%)=100 \times \frac{F_{\text {inlet }}-F_{\text {outlet }}}{F_{\text {inlet }}} \\
& \text { Selectivity }\left(C_{n} H_{m} O_{s}\right)=\frac{n \times N\left(C_{n} H_{m} O_{s}\right)}{\sum n \times N\left(C_{n} H_{m} O_{s}\right)}
\end{aligned}
$$

, where $\mathrm{F}_{\text {inlet }}$ and $\mathrm{F}_{\text {outlet }}$ are the flow rates of the reactant at the inlet and outlet of reactor, respectively. $\mathrm{N}\left(\mathrm{C}_{n} \mathrm{H}_{m} \mathrm{O}_{s}\right)$ represents the molar percentage of $\mathrm{C}_{n} \mathrm{H}_{m} \mathrm{O}_{s}$ among products detected by FID, and $\mathrm{n}$ is the number of carbons in $\mathrm{C}_{\mathrm{n}} \mathrm{H}_{\mathrm{m}} \mathrm{O}_{\mathrm{s}}$.

1. J. Liu, H. Xue, X. Huang, P.-H. Wu, S.-J. Huang, S.-B. Liu and W. Shen, Chinese Journal of Catalysis, 2010, 31, 729-738. 


\section{Reversibility derivation for decarbonylation of acetic acid}

Assuming that decarbonylation of acetic acid is a reversible reaction, the equation is:

$$
2 \mathrm{CH}_{3} \mathrm{COOH}=\mathrm{CH}_{3} \mathrm{COOCH}_{3}+\mathrm{CO}+\mathrm{H}_{2} \mathrm{O}
$$

The result from Figure.3b showed that the formation rate is independent with partial pressure of acetic acid, therefore, the kinetic expression for methyl acetate formation is:

$$
\mathrm{r}_{\text {methyl acetate }}=\mathrm{r}_{\text {methanol }}=\mathrm{k}_{+} P_{\text {acetic acid }}^{0}
$$

Methyl acetate in this reaction is obtained by esterification of methanol with acetic acid, and the concentration of methanol in effluent is much smaller than that of methyl acetate, therefore, equation (2) could be also used for the formation of methanol.

As presented in Figure.5c, increasing $\mathrm{CO}$ partial pressure linearly suppresses the formation rate of methyl acetate because of methanol carbonylation, therefore the expression for the reversed direction is:

$$
\mathrm{r}_{\text {acetic acid }}=\mathrm{k}_{-} P_{\text {methanol }}^{0} P_{C O}^{1}
$$

The reaction order for this reaction follows reported literature ${ }^{2}$. The overall expression for formation of methyl acetate is:

$$
\mathrm{r}=\frac{\mathrm{dC}}{\mathrm{dt}}=\mathrm{k}_{+}-\mathrm{k}_{-} P_{C O}^{1}
$$

The initial value of amount of acetic acid $\mathrm{N}_{\mathrm{A}}$, the converted amount of acetic acid, $2 \mathrm{n}$, and the generated amount of $\mathrm{CO}, \mathrm{n}$ :

$$
\frac{\mathrm{d}\left(\mathrm{N}_{\mathrm{A}}-2 \mathrm{n}\right)}{\mathrm{dt}}=\mathrm{k}_{+}-\mathrm{k}_{-} \mathrm{n}
$$

When the reaction reaches equilibrium, $2 n_{e}$ of acetic acid are consumed and $n_{e}$ of $C O$ are generated:

$$
\frac{\mathrm{d}\left(\mathrm{N}_{\mathrm{A}}-2 \mathrm{n}_{\mathrm{e}}\right)}{\mathrm{dt}}=\mathrm{k}_{+}-\mathrm{k}_{-} \mathrm{n}_{\mathrm{e}}=0
$$




$$
\mathrm{k}_{-}=\mathrm{k}_{+} / \mathrm{n}_{\mathrm{e}}
$$

Substitute Eq.7 to Eq.5:

$$
\frac{\mathrm{d}\left(\mathrm{N}_{\mathrm{A}}-2 \mathrm{n}\right)}{\mathrm{dt}}=\mathrm{k}_{+}-\frac{\mathrm{k}_{+}}{\mathrm{n}_{\mathrm{e}}} \mathrm{n}=\mathrm{k}_{+}\left(1-\frac{1}{\mathrm{n}_{\mathrm{e}}} \mathrm{n}\right)
$$

The integration of Eq.8:

$$
-\ln \left(1-\frac{1}{\mathrm{n}_{\mathrm{e}}} \mathrm{n}\right)=\frac{1}{2} \mathrm{k}_{+} \mathrm{t}+\mathrm{D}
$$

Where D is an constant, and the exponential form of Eq.9 is:

$$
\mathrm{n}=\mathrm{A}-\mathrm{B} \mathrm{e}^{-\mathrm{Ct}}
$$

Due to the equal amount of methyl acetate and CO, Eq.10 can be also used to describe formation rate of methyl acetate with time. Eq.10 and the fitted equation for the formation of methyl acetate in Figure. 3d share the same format.

2. P. Cheung, A. Bhan, G. J. Sunley and E. Iglesia, Angewandte Chemie International Edition, 2006, 45, $1617-1620$. 
Table.S1 Channel dimension of zeolites used in this study

\begin{tabular}{|c|c|c|}
\hline Zeolites & Channel openings a,b & Channel dimensionality \\
\hline $\mathrm{H}-\mathrm{Y}$ & [111] 12M.R. 7.4×7.4 $\AA$ & 3-dimensional \\
\hline H-Beta & $\begin{array}{l}\text { [100] 12M.R. } 6.6 \text { x } 6.7 \AA ̊ \\
\text { [001] 12M.R. 5.6×5.6 }\end{array}$ & 3-dimensional \\
\hline H-ZSM5 & $\begin{array}{l}\text { [100] 10M.R. } 5.1 \times 5.5 \AA \\
\text { [010] 10M.R. } 5.3 \times 5.6 \AA\end{array}$ & 3-dimensional \\
\hline H-ZSM35 & $\begin{array}{l}\text { [001] 10M.R. 4.2 ×5.4 } \\
\text { [010] 8M.R. } 3.5 \times 4.8 \AA\end{array}$ & 2-dimensional \\
\hline H-MOR & $\begin{array}{c}\text { [001] 12M.R. } 6.5 \times 7.0 \AA ̊ \\
\text { [001] 8M.R. } 2.6 \times 5.7 \AA \delta\end{array}$ & 2-dimensional \\
\hline
\end{tabular}

${ }^{\mathrm{a}}$ These data are obtained from http://www.iza-online.org/. ${ }^{\mathrm{b}}$ M.R. is the abbreviation of -membered ring, e.g. 12M.R. represents 12-membered ring.

Table.S2 Surface Area and Pore volume of NaH-MOR samples

\begin{tabular}{|c|c|c|}
\hline Zeolites & Surface Area $\left(\mathrm{m}^{2} \mathrm{~g}^{-1}\right)$ & Pore volume $\left(\mathrm{cm}^{3} \mathrm{~g}^{-1}\right)$ \\
\hline $1 \#$ & 337.57 & 0.21 \\
\hline $2 \#$ & 348.94 & 0.21 \\
\hline $3 \#$ & 362.56 & 0.22 \\
\hline $4 \#$ & 360.01 & 0.23 \\
\hline $5 \#$ & 351.42 & 0.22 \\
\hline $6 \#$ & 360.62 & 0.22 \\
\hline Parent Sample & 347.15 & 0.22 \\
\hline
\end{tabular}



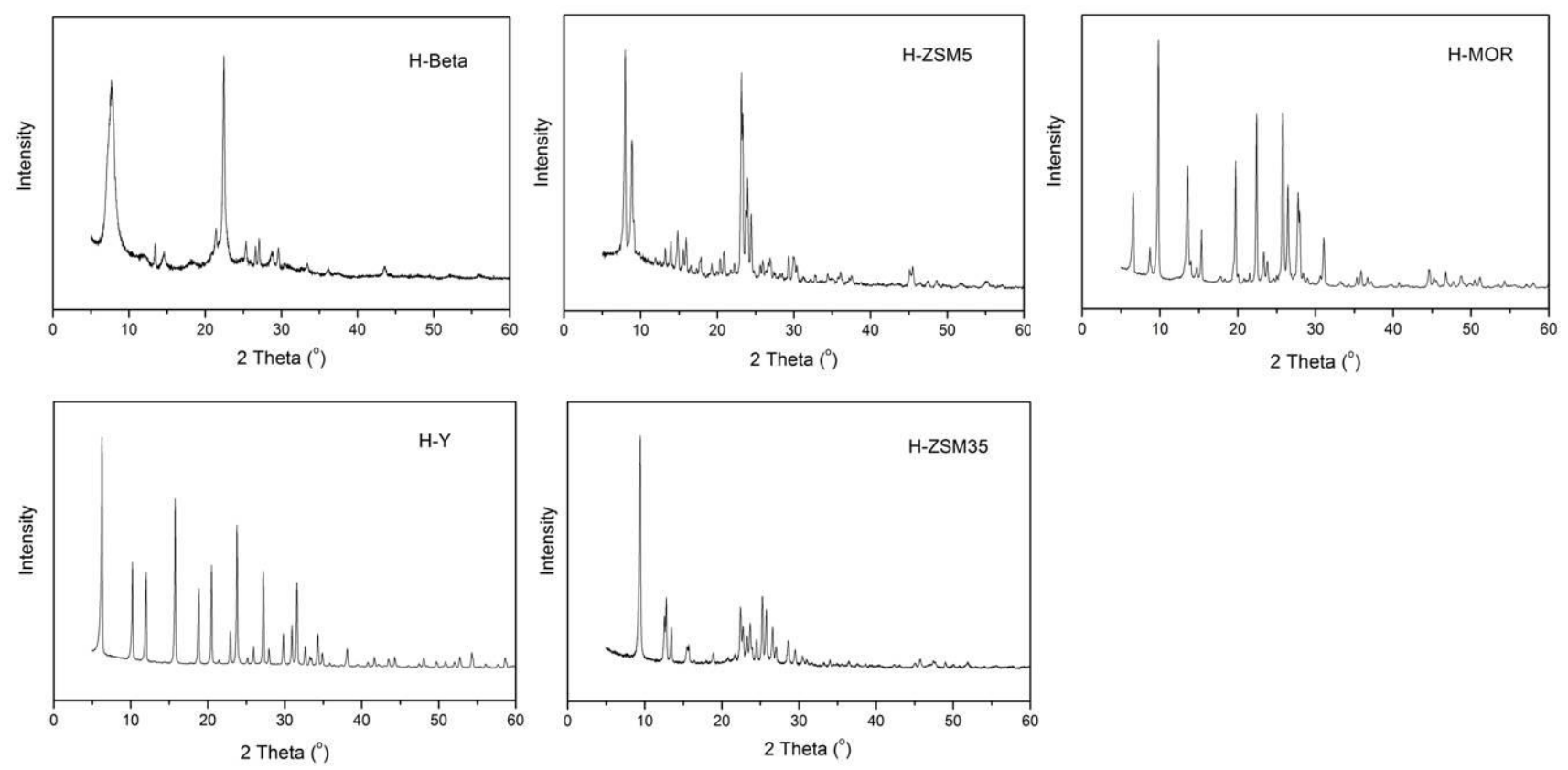

Figure.S1 XRD characterization of zeolites

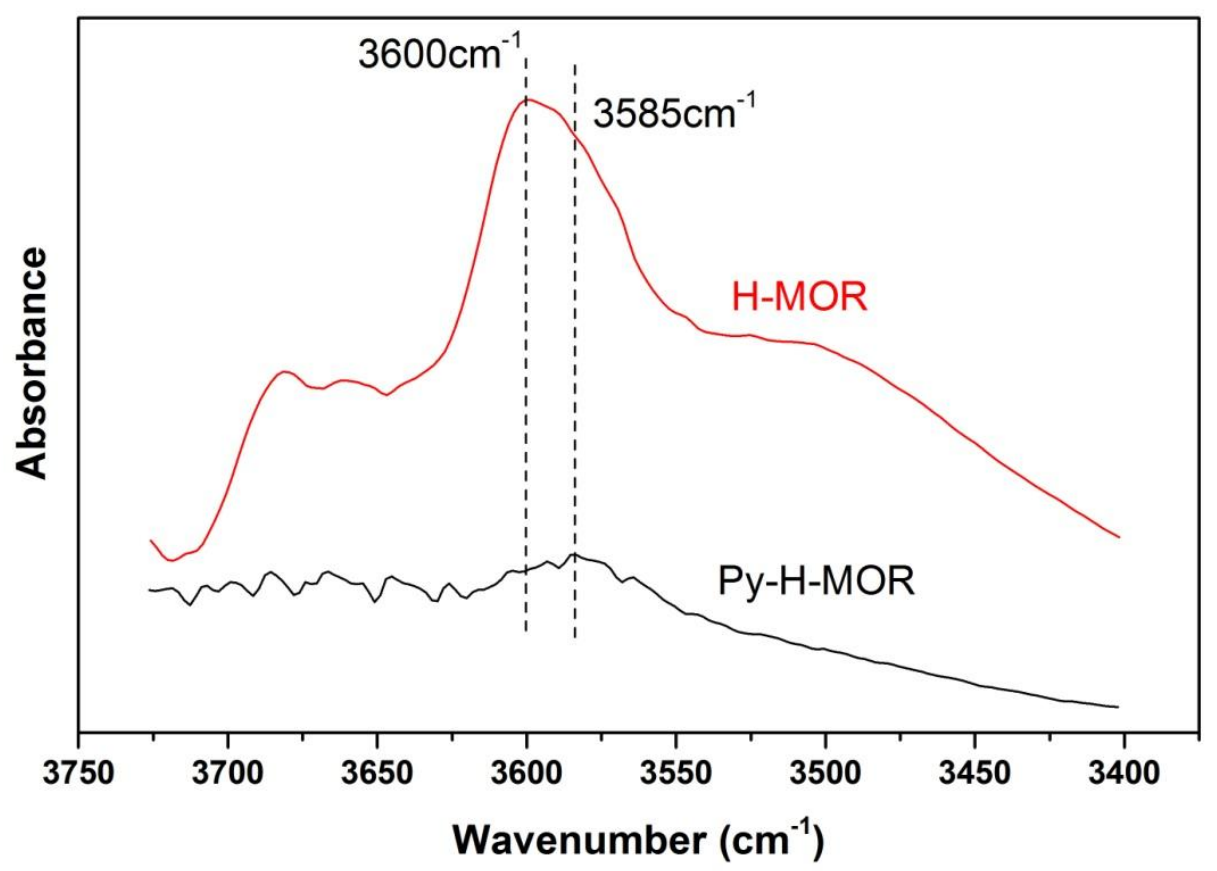

Figure.S2 The IR spectra of H-MOR and py-H-MOR at $473 \mathrm{~K}$. 


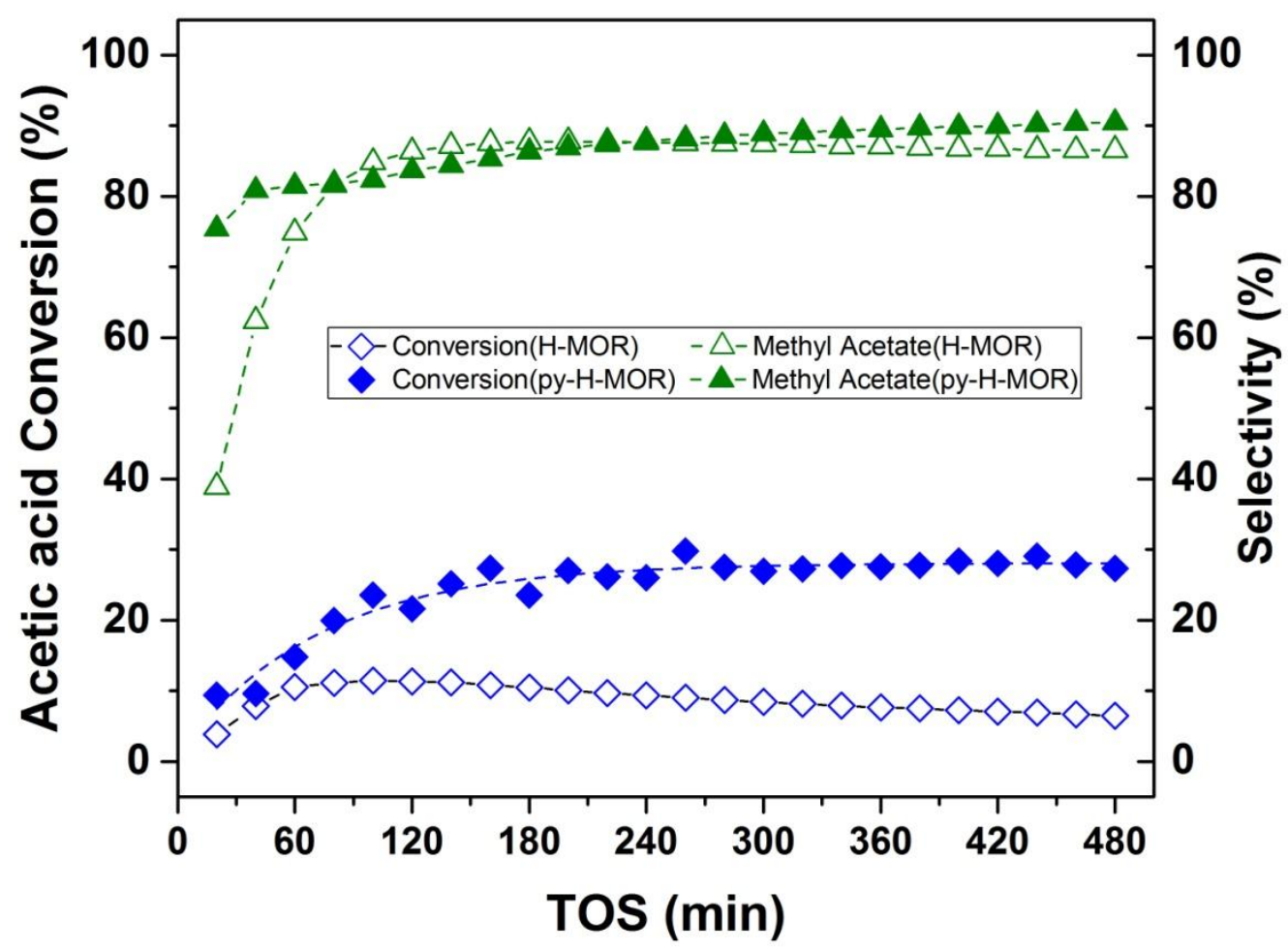

Figure.S3 Time-on-stream of acetic acid decarbonylation. $593 \mathrm{~K}, 1$ bar, $P_{\text {acetic acid }}=6 \mathrm{kPa}$, total GHSV $=3000 \mathrm{~h}^{-1}$ and Ar was used as balancing gas.

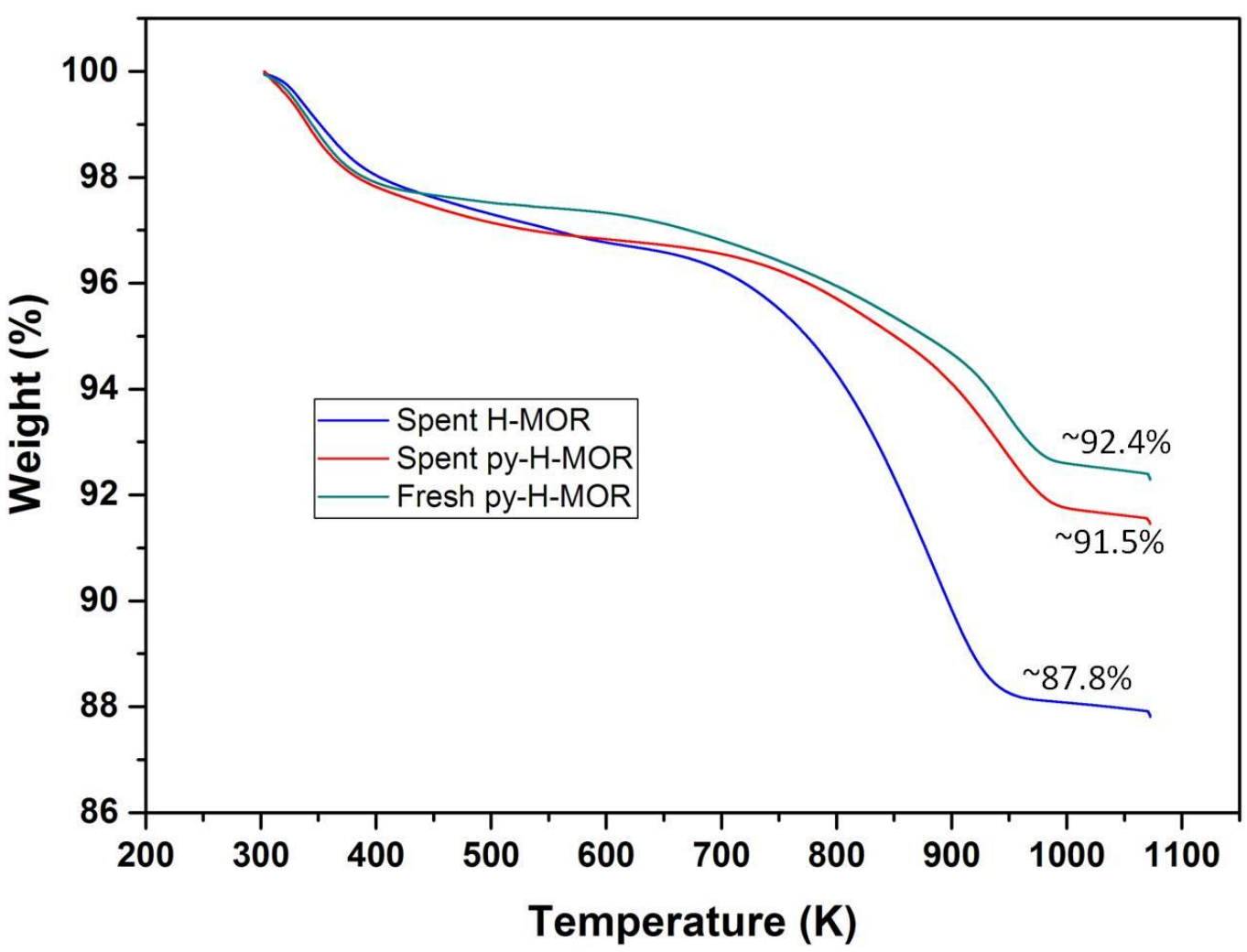

Figure.S4 TG analysis of H-MOR and py-H-MOR 


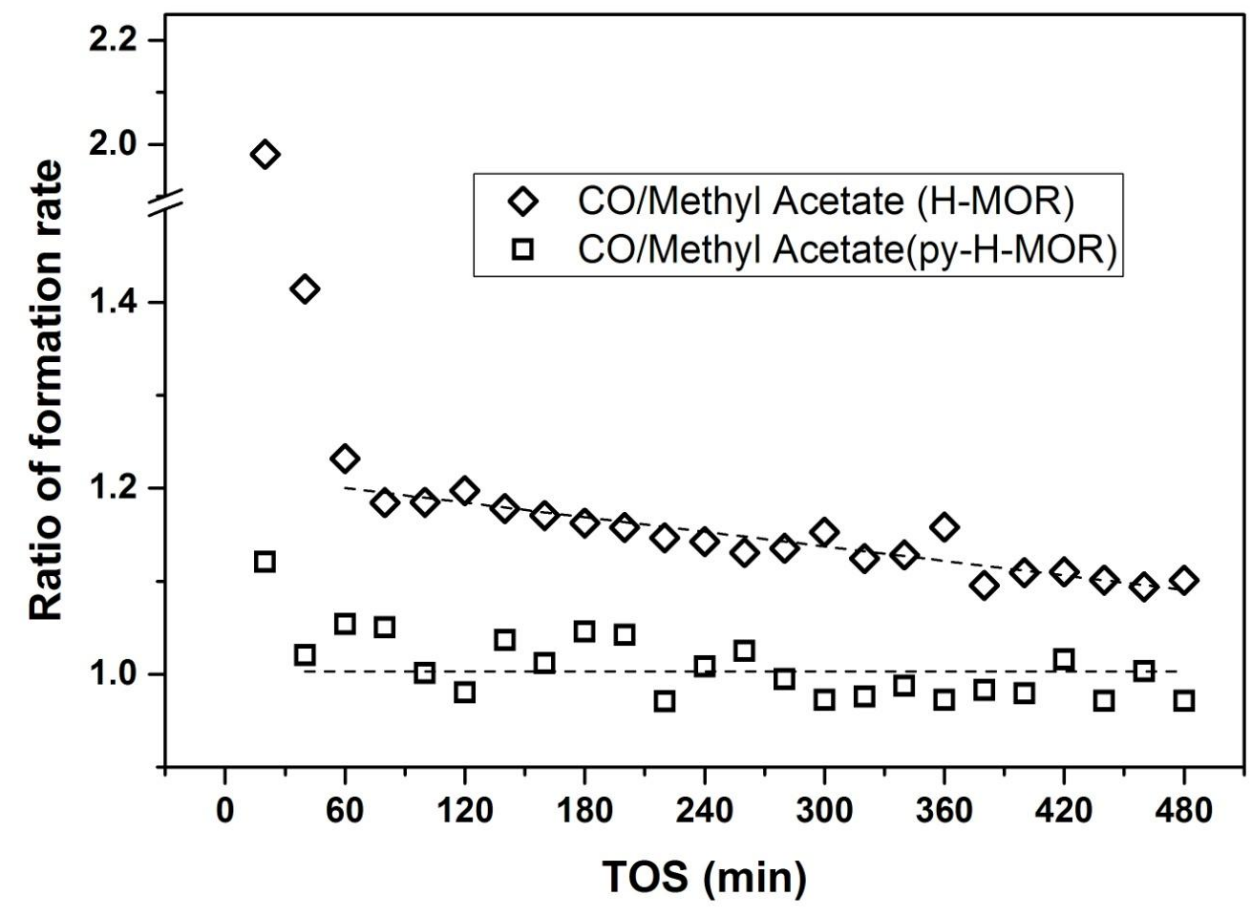

Figure.S5 Ratio of formation rate of CO to methyl acetate

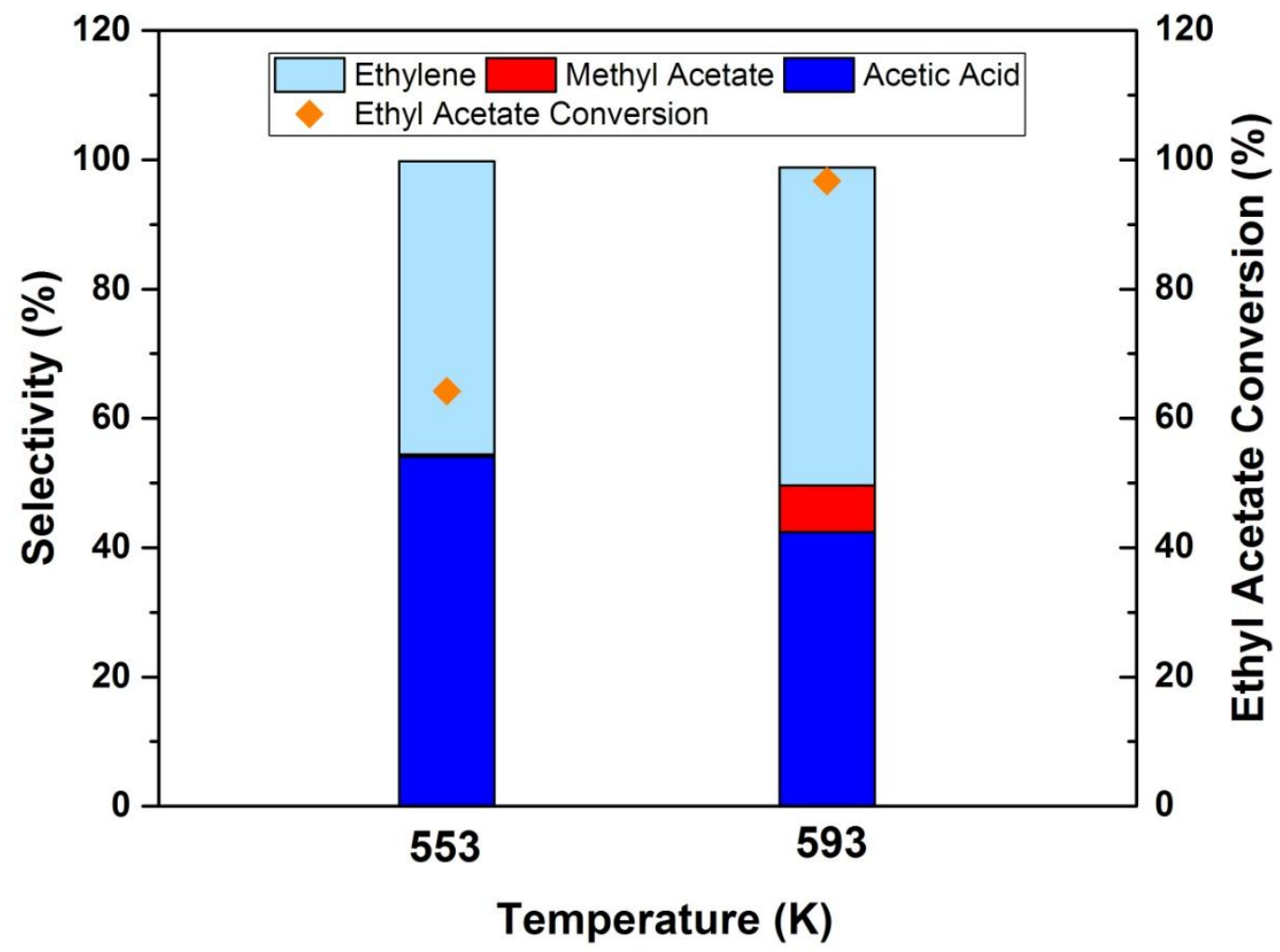

Figure.S6 Reaction of ethyl acetate. 1 bar, GHSV $=3600 \mathrm{~h}^{-1}, P_{\text {ethyl acetate }}=6.7 \mathrm{kPa}$, Py-H-MOR was used as catalysts and Ar was used as balancing gas. 


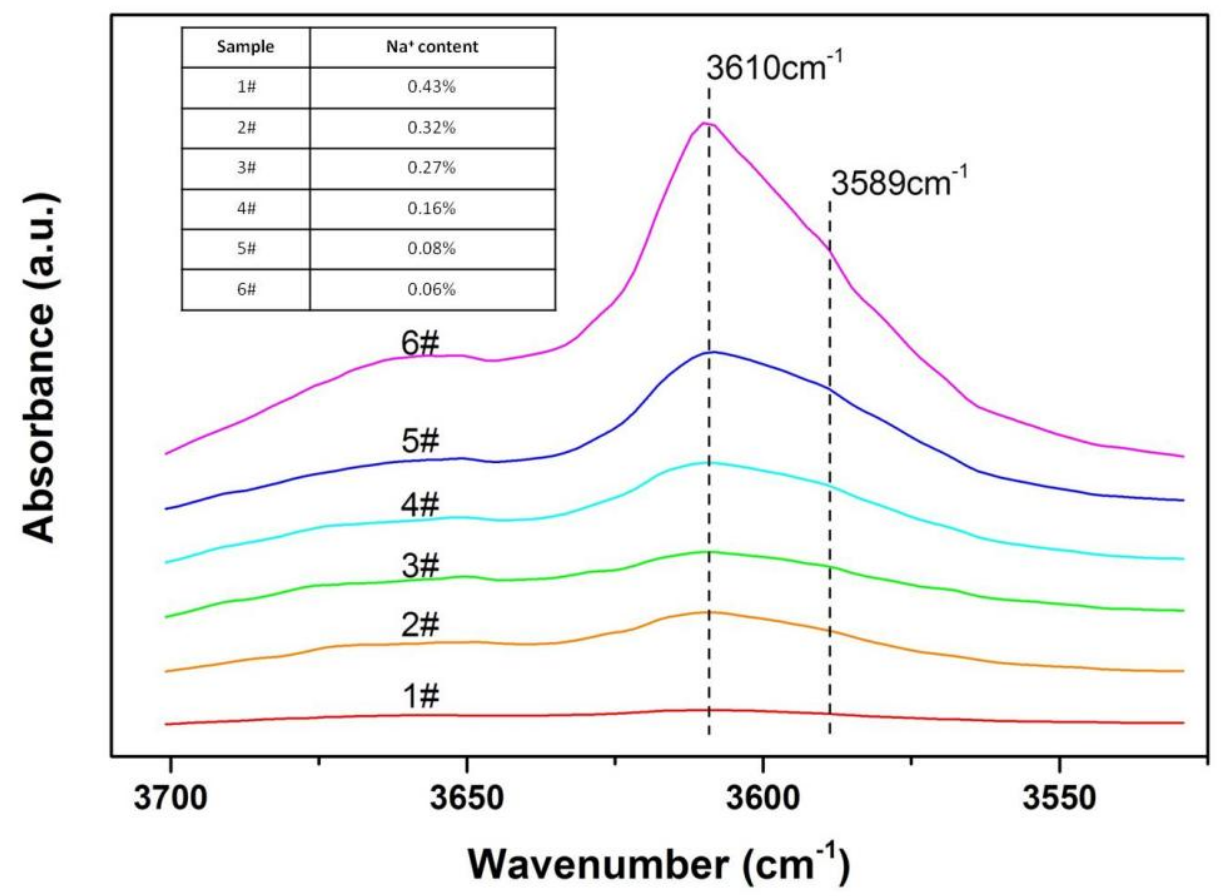

Figure.S7 IR spectra of NaH-MOR at $473 \mathrm{~K}$ and their $\mathrm{Na}^{+}$content

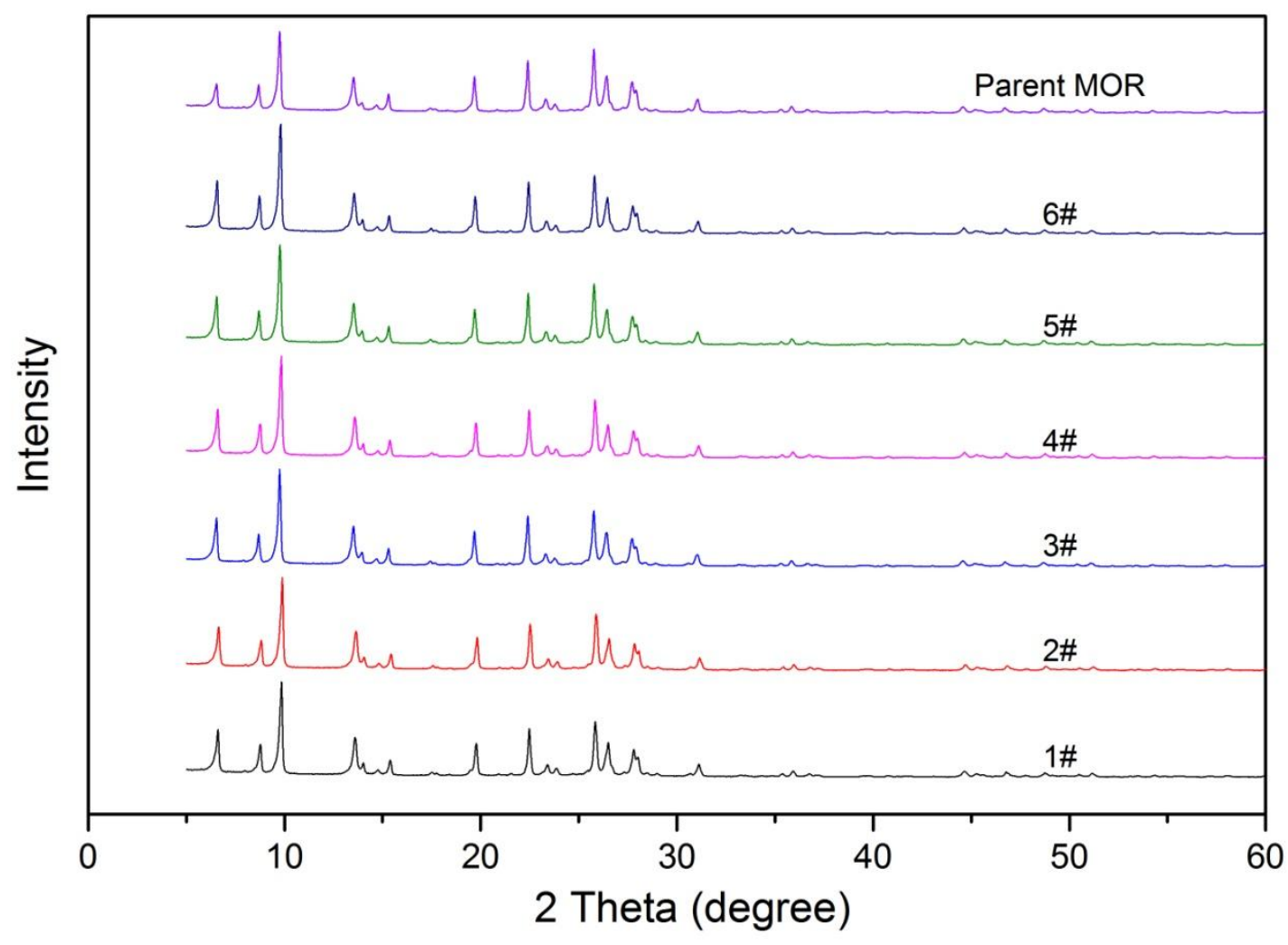

Figure.S8 XRD characterization of NaH-MOR and their parent sample 


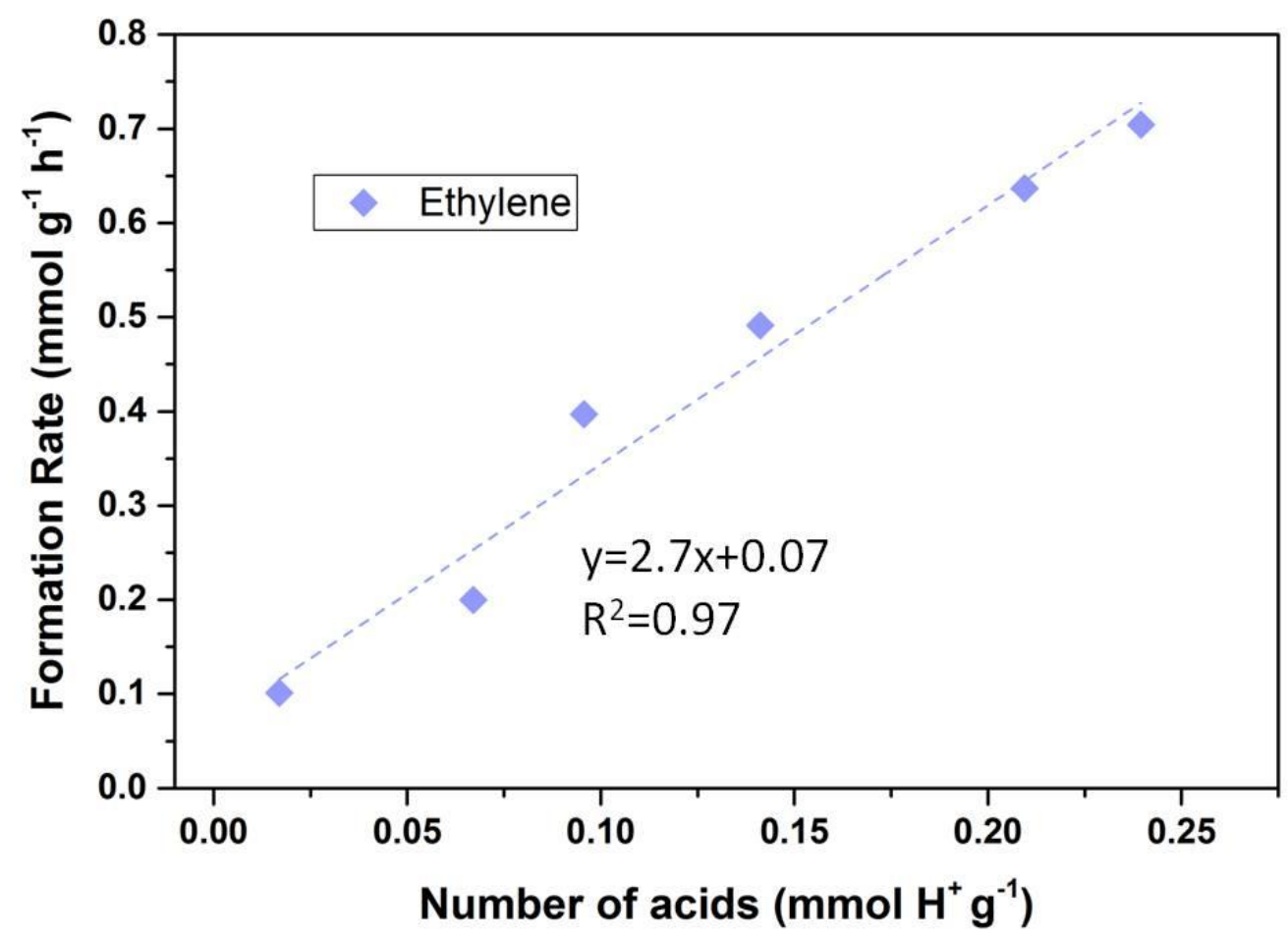

Figure.S9 Correlation between number of acids within 8M.R. side pocket of H-MOR and the formation rate of ethylene. $613 \mathrm{~K}, 1$ bar, $P_{\text {propionic } \text { acid }}=3 \mathrm{kPa}$, total GHSV=3000 $\mathrm{h}^{-1}$ and $\mathrm{Ar}$ was used as balancing gas, pyridine treated $\mathrm{NaH}-\mathrm{MOR}$ samples were used as catalysts.

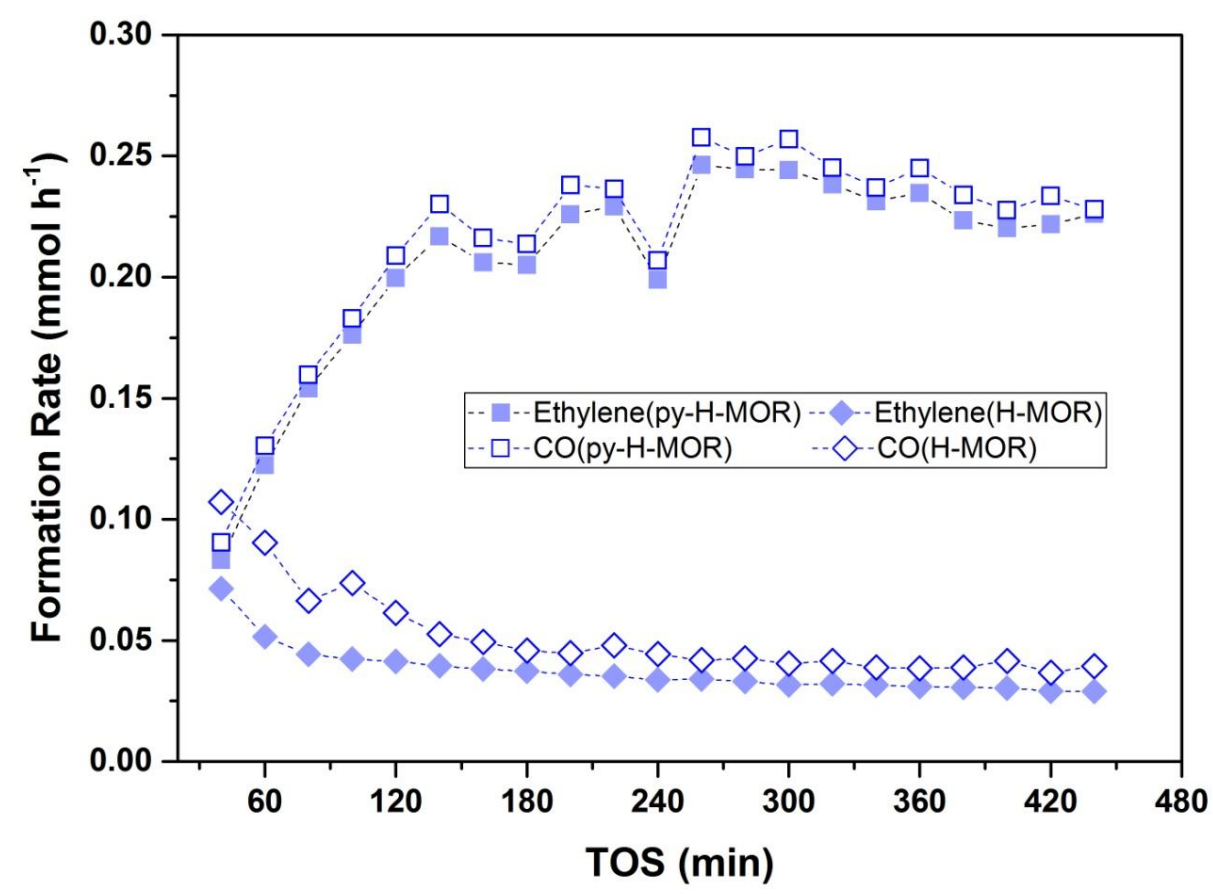

Figure.S10 Formation rate of $\mathrm{CO}$ and ethylene. $613 \mathrm{~K}, 1 \mathrm{bar}, P_{\text {propionic acid }}=3 \mathrm{kPa}$, total GHSV $=3000 \mathrm{~h}^{-1}$ and Ar was used as balancing gas. 


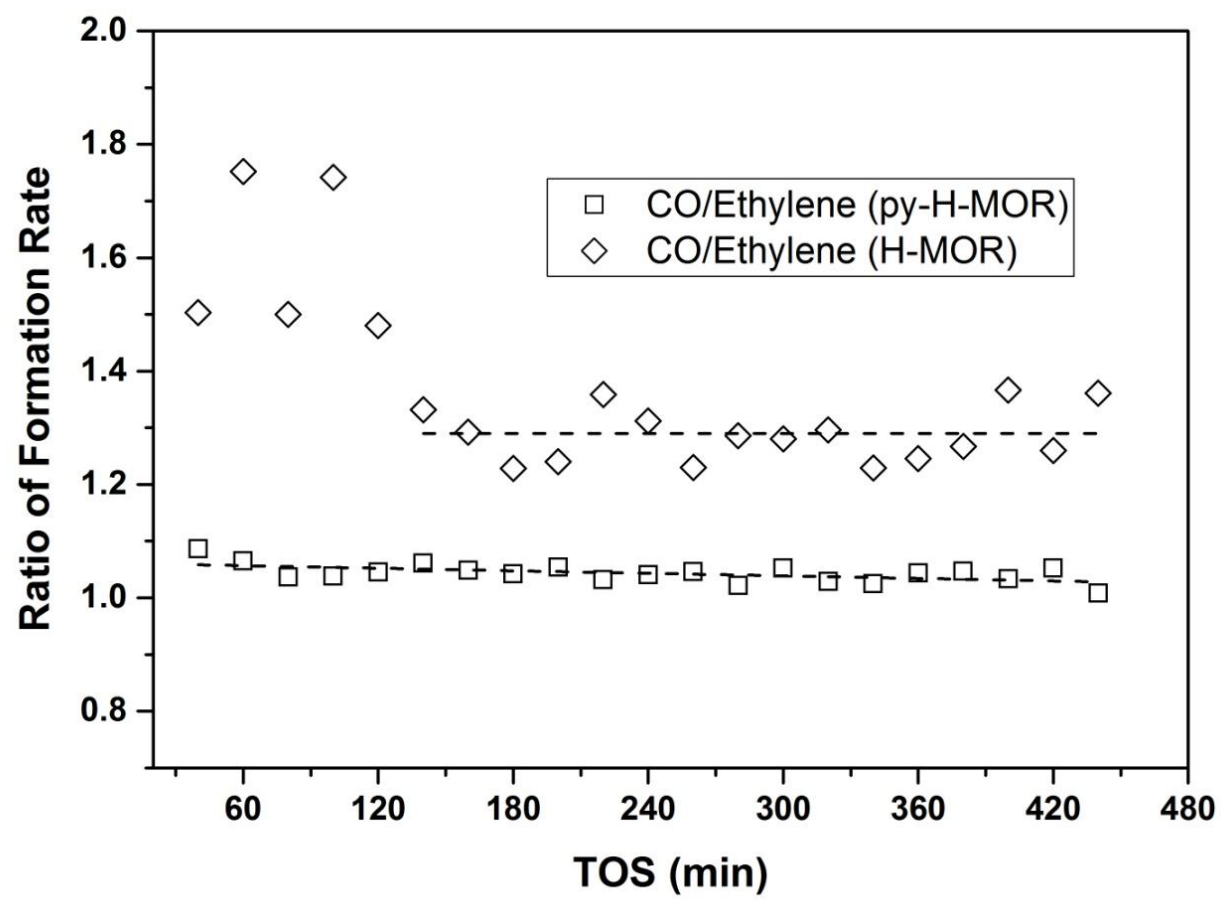

Figure.S11 Ratio of formation rate of CO to ethylene.

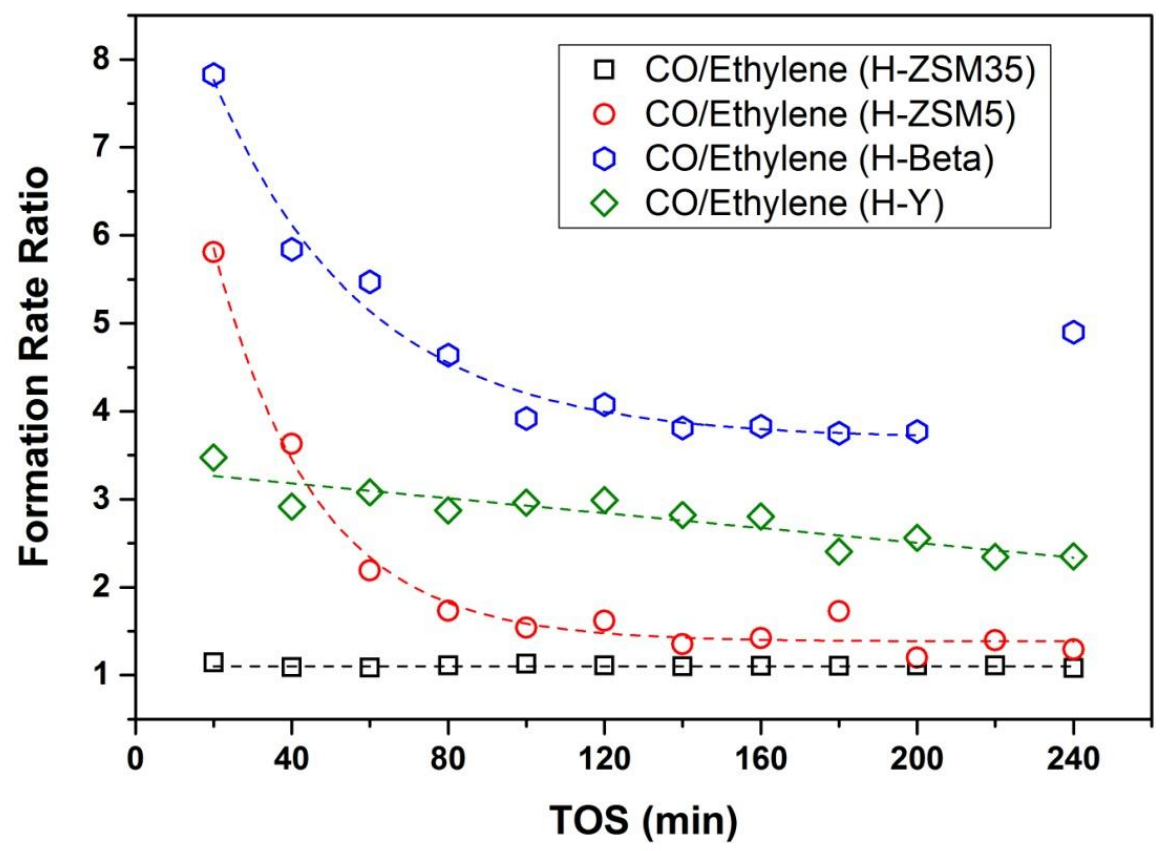

Figure.S12 Ratio of formation rate of CO to ethylene over H-ZSM5, H-ZSM35, H-Beta and H-Y. $613 \mathrm{~K}, 1$ bar, $P_{\text {propionic acid }}=3 \mathrm{kPa}$, total $\mathrm{GHSV}=1500 \mathrm{~h}^{-1}$ and $\mathrm{Ar}$ was used as balancing gas. 


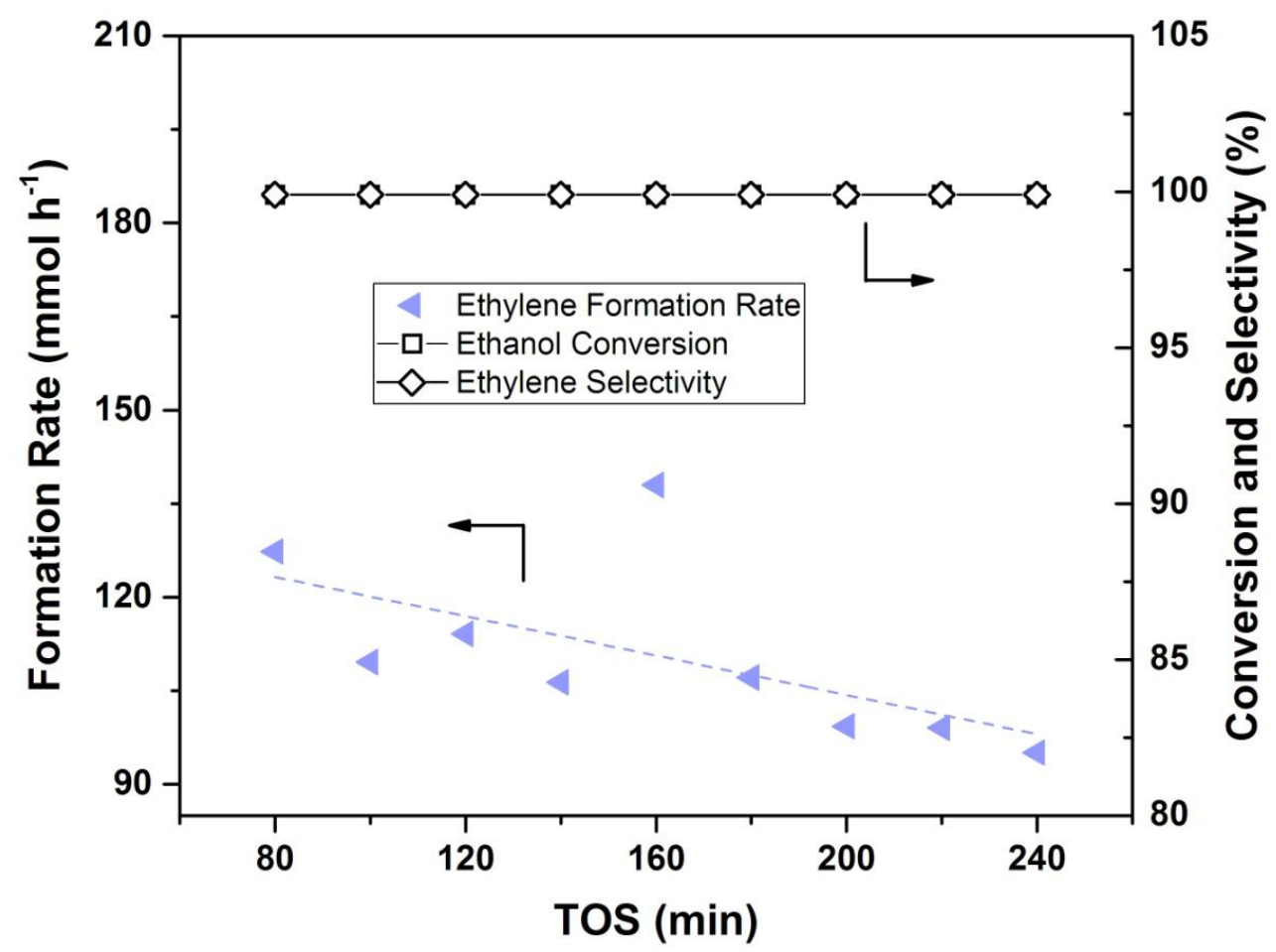

Figure.S13 Capacity of ethanol dehydration over py-H-MOR. $P_{\text {ethanol }}=90 \mathrm{kPa}, 613 \mathrm{~K}, 1 \mathrm{bar}$, GHSV $=3000 \mathrm{~h}^{-1}$, py-H-MOR was used as catalyst and Ar was used as balancing gas.

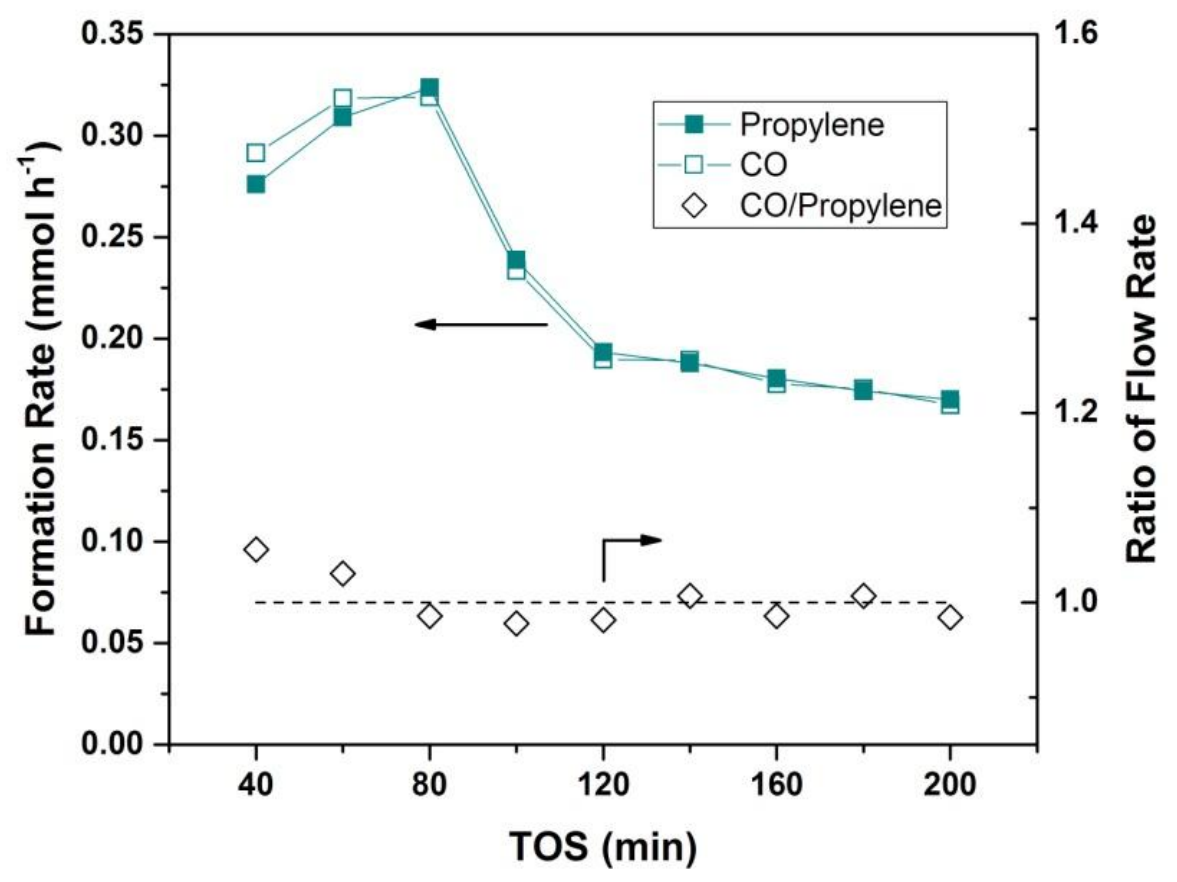

Figure.S14 Formation rate of $\mathrm{CO}$ and propylene and the ratio of $\mathrm{CO}$ to propylene. $633 \mathrm{~K}, 1$ bar, $P_{\text {butanoic acid }}=6 \mathrm{kPa}$, total GHSV $=1875 \mathrm{~h}^{-1}$ and Ar was used as balancing gas. 